\title{
The Value and Cultivation of Cultural Empathy Ability in Intercultural Communication
}

\author{
Xiao Yang \\ Xijing University, Shaanxi, Xi'an, 710100
}

Keywords: value; cultivation; cultural empathy ability; intercultural communication

\begin{abstract}
Cultural empathy is the most important factor in intercultural communication. Cultural empathy directly affects the quality, effectiveness and progress of intercultural communication. Fully understanding the value of cultural empathy ability, consciously cultivating and improving cultural empathy ability in practice has extremely important theoretical and practical significance for intercultural communication.
\end{abstract}

\section{Introduction}

Intercultural communication is an important means to promote the spread of national culture and a medium for promoting the exchange of ethnic and non-national cultures. In intercultural communication, cultural empathy ability can not be underestimated, which affects the process, effect and quality of intercultural communication. Therefore, in university teaching, students must overcome the errors of fear, superiority, racial discrimination and religious discrimination in the process of communication, thus establishing a link between the exchange of national and non-national cultures and the realization of globalization.

With the continuous improvement of China's comprehensive national strength and international influence, the frequency of foreign-related exchanges in China has increased, the scale has been expanded, and the increase in international exchange has made cross-cultural communication more and more important. In essence, cross-cultural communication is a comprehensive ability that not only requires intercultural communicators to have a sound knowledge and competence system, but also requires communicators to have flexible thinking and resilience. Intercultural communicators must not only accept foreign cultures, but also dare to tolerate certain uncertain situational factors in intercultural communication. The above traits and abilities will eliminate and resolve the cultural centers that are uncontrollable in intercultural communication. Doctrine and cultural prejudice play a certain role in promoting the smooth progress of intercultural communication, all of which cannot be separated from the cultivation of cultural empathy ability in intercultural communication. As a core component of the intercultural communicative competence training system, cultural empathy has a significant influence on the effect and process of intercultural communication. To avoid the multidimensional obstacles in intercultural communication, we must face up to the cultural empathy ability [1].

\section{The Value of Cultural Empathy in Intercultural Communication}

Intercultural communication is a key study of the effective communication and communication between different cultures. It is necessary and necessary to focus on issues such as cultural empathy and cultural empathy. If the cognitive and emotions of the communicative subject cannot get rid of the influence of the mindset formed by their own local cultural accumulation, and rush to the constraints of the cognitive similarity framework caused by their own psychological projections, they will stand on the other side's fair and objective position, that is, To carry out effective cultural empathy, we must consciously avoid cultural conflicts caused by cultural differences, let multiculturalism achieve new construction through the integration, infiltration and mutual feedback, and finally emerge into diverse and different ideal realms.

In intercultural communication, the communicative subjects of different cultural backgrounds 
make their information coding and decoding, speech and non-verbal because of their cultural characteristics, values, religious beliefs, ethical norms, ways of thinking, and lifestyle. Behavior, language use patterns, text organization structure and many other aspects show differences. It is impossible to face, perceive, and mediate these cultural differences due to cultural differences. In cross-cultural communication, misunderstandings, prejudice, disputes, frictions, and contradictions are easily caused. This is also the need for cultural empathy and the need to improve cultural migration in intercultural communication [2].

The existence of cultural differences is both objective and very normal. It is precisely because of the diversity and diversity of culture that it shows the richness and vividness of culture, and makes the culture of diversity show great vitality in its development. The diversity of cultures promotes competition among different cultures, prompts people to see the strengths of learning from heterogeneous cultures, induces people's inspiration to promote cultural innovation, and therefore, without cultural diversity and diversity, Without the richness and innovation of culture, there is no need for cultural empathy and the ability to improve cultural empathy. Globalization has exacerbated the diversity and diversity of human culture. The phenomenon of one-person multi-site system and one-person multi-time system will become more and more common. Only by consciously carrying out cultural empathy, transcending the shackles of local culture in terms of psychology and emotions, and being a multicultural person can effectively live in harmony with people of different cultural backgrounds, reduce cultural friction and adapt to the needs of social development. In college English teaching, attaching importance to cultural empathy and enabling students to master the art and methods of cultural empathy is to improve their comprehensive English application ability, reduce cultural conflicts caused by cultural errors in cross-cultural communication, and achieve two-way smooth communication.

The concept of empathy has expanded from aesthetics to cognitive psychology and intercultural communication. However, the discussion of this complex phenomenon is still a matter of opinion and wisdom. The views summarized from previous studies are endless. Empathy is far from being a simple variable or factor. Summarizing previous research, it is necessary to discuss the potential roles and functions of the empathy process [3].

Different countries and nations have their own social systems, customs, values, national cultures, religious beliefs, etc. Words and deeds and nature are different. Intercultural communicators can only adapt themselves to various specific types if they face up to the above cultural differences. Culture, constantly adjusting in various cultural communication processes, and finding a balance point of communication, can avoid misconduct in intercultural communication, and make the subject of intercultural communication get rid of the national culture from the level of cognition and perception. The inevitable difference between exotic culture and local culture, as well as the communication friction caused by the difference between the two cultures, is the reason for the cultural empathy ability of the communicative subject in intercultural communication.

Cultural empathy can highlight national culture in intercultural communication and achieve communication purposes through linguistics and semiotics. Ethnic groups from different countries and regions have their own cultural backgrounds and characteristics. To improve the cultural empathy ability of intercultural communication subjects, we must objectively and rationally treat ethnic cultures between different regions, respect social etiquette, values, and moral standards. Foreign cultures and local cultures have different perceptions of olfactory information, avoiding misunderstandings of intercultural communication caused by cultural differences.

One of the important contents of cultural empathy training is values. Cultural empathy is conducive to eliminating the negative values of communicative subjects, improving their enthusiasm, enhancing the ability of communicative subjects to distinguish culture and dialectical thinking, and improving the perception of different cultural differences and connotations. And cognition, under the premise of the culture of the native culture, to embrace the foreign culture, to enable the communicative subjects to communicate with the correct emotional cognition attitude, to cope with various situations in communication, these are cultural empathy ability to intercultural communication the role and value [4]. 


\section{The Cultivation of Cultural Empathy Ability in Intercultural Communication}

Cultural empathy ability is an important part of intercultural communication. It can close the distance between national culture and non-national culture, and realize the transformation between cultures by setting language situations, thus promoting communication and communication. Cultural empathy is an ability that is acquired through post-natal training in a specific environment. The cultivation of this ability requires strong perseverance and patience, requires full commitment, and fosters cultural sensitivity and cultural compliance of the communicative subject.

Cultivate the cultural sensitivity of communicative subjects first, understand ethnic customs, and shorten interpersonal distance. Cultural sensitivity is an important means to improve the ability of cultural empathy. By cultivating people's understanding of different cultural backgrounds in different situations, interpersonal distance can be reduced. Because communicative subjects are often influenced by their own cultures when they accept foreign information, they understand the non-ethnic environment according to the atmosphere of the national environment, thus making non-standard behaviors. For example, in our cultural environment, when we meet with our guests, we will say hello to each other. If a guest takes a kiss in the form of a cheek, the receptionist will be very angry, but in the Arab countries this is a friendly custom. Therefore, when integrating into different cultural situations, it is necessary to understand the cultural customs of different situations and to draw closer to each other's interpersonal distances in order to enhance cultural sensitivity and smoothly realize cultural empathy.

In order to improve cultural sensitivity, it is necessary to shorten the cognitive distance between different cultural subjects and to understand the custom requirements of different background cultures by strengthening culturally sensitive training. For example, the phrase "goodbye" is goodbye in most countries, but it is welcome in some countries. This is the distance gap caused by national culture. Compensating will lead to unnecessary disputes.

Second, adapt to different cultural environments. By adapting to different cultural environments, it is possible to improve the response and adaptability of communicative subjects to different cultural environments, and to be able to experience the differences in cultural background in the first place. Fully understand the beliefs, ethnic worships, behavioral habits and ways of different ethnic groups, ethnic groups, understanding the modes of thinking between each other, accepting differences in each other's existence in a friendly manner, customizing cultural diversity and cultural differences, and improving cultural sensitivity The height is increased to the level of fusion culture, so that the skills of cultural sensitivity can be skillfully applied in intercultural communication, unnecessary cultural friction can be reduced, and cultural differences can be adapted from social norms, linguistic laws and cultural rules. Ethnic contradictions promote the feelings between cultural communicators and can communicate harmoniously and harmoniously.

Third, improve sensitivity. Improve cultural sensitivity by increasing the perceived sensitivity of communicators. Different ways of perception form differences in cross-cultural communication. According to Samwa's research, five factors, such as mentality system, social organization, world outlook, values, and belief, affect the communicative ability of communicators. Enhancing from these five aspects is conducive to improving communicative intercultural communication ability. In intercultural communication, two people who need to understand each other and know each other's cultural situation must care about the objects they communicate with, and use the sixth sense to identify and perceive communicators, and conduct scientific analysis and research to avoid artificial the destruction of multicultural communication and the quality of cultural communication.

Another manifestation of cultural empathy is cultural adaptability. Therefore, in the cultivation of cultural empathy, it is necessary to cultivate the cultural adaptability of communicators. According to Samwa's research, if there is no difference between cultural communicators in different cultural situations, then this cultural situation can be simplified. By unifying the characteristics to determine the overall characteristics of the group, this method is generally considered to be a rigid model and a means of psychological defense. Therefore, in order to understand the difference between yourself and others, it is necessary to overcome the nature of communication. Generate stereotypes and increase cultural sensitivity for cultural communication and communication. 
From the different literary writers and works, Zhan Mingxin discovered that the so-called "world literature" is not a classic literature, but a literary form that transcends national borders, races above all contexts, and can communicate and communicate. Goethe once emphasized the connection and thinking of different literary circles in this form in many articles. Therefore, the content contained in the multicultural context will definitely not be the content of dispelling center, non-marginalization and non-territory [5].

Cultivating cultural adaptability can quickly improve the perception of the culture of each nation, so that the role of cultural empathy can be reflected, and thus achieve cross-cultural communication. The cultural empathy ability in intercultural communication is carried out in a specific cultural context. It has the function of strengthening communication and promoting communication. It has unique personality and tension in multicultural context, and can deeply understand foreign cultural thoughts and simplify communication boundaries. . This paper analyzes the value of cultural empathy ability in intercultural communication, and reflects the importance of cultural empathy in intercultural communication, and adopts effective methods to cultivate cultural empathy in intercultural communication, making it different. In the cultural environment, we can communicate well with non-ethnic cultural communicators, realize cultural diversity, and promote the integration and development of world culture.

\section{Conclusion}

The cultivation of cultural empathy ability is inseparable from the cultural differences teaching activities carefully designed by teachers in the classroom. At the same time, it is necessary for learners to use extracurricular time to enrich language and culture knowledge and participate in cultural practice activities. These are effective training of cultural empathy ability. Cultivating cultural empathy ability is an arduous task. It requires us to continuously explore in the future teaching, and establish a set of effective strategies for cultivating cultural empathy ability, so as to promote the improvement of foreign language learners' foreign language communication ability.

\section{References}

[1] Liu Junqi. Cultural Empathy Ability and Its Cultivation in Intercultural Communication [J]. Theoretical Journal, 2012, (1): 96-97.

[2]Yuan Weiliang. Moderate Cultural Empathy in Intercultural Communication [J].Journal of Anyang Institute of Technology, 2010, 9(1):92-94.

[3] Dong Fang. A Comparative Study of Cultural Differences between China and the West in the Background of Intercultural Communication [J]. Theoretical Observations, 2012, (4): 37-38.

[4] Liu Jing, Song Deyun. On the Cultivation of Foreign Language Learners' Cultural Empathy Ability [J]. China Electric Power Education, 2012, (20).234

[5] Chen Erchun, Yuan Zhiming. Research on Cultural Empathy Ability and Cross-cultural Consciousness [J].Journal of Sichuan International Studies University, 2008, 24(3):138-140. 